\title{
Development of a High Quality Kicker Magnet System
}

J. Dinkel, B. Hanna, C. Jensen, D. Qunell and R. Reilly

Fermi National Accelerator Laboratory

P.O. Box 500, Batavia, Illinois 60510

May 1993 


\section{Disclaimer}

This report was prepared as an account of work sponsored by an agency of the United States Government. Neither the United States Government nor any agency thereof, nor any of their employees, makes any warranty, express or implied, or assumes any legal liability or responsibility for the accuracy, completeness, or usefulness of any information, apparatus, product, or process disclosed, or represents that its use would not infringe privately owned rights. Reference herein to any specific commercial product, process, or service by trade name, trademark, manufacturer, or otherwise, does not necessarily constitute or imply its endorsement, recommendation, or favoring by the United States Government or any agency thereof. The views and opinions of authors expressed herein do not necessarily state or reflect those of the United States Government or any agency thereof. 


\title{
Development of a High Quality Kicker Magnet System
}

\author{
J. Dinkel, B. Hanna, C. Jensen, D. Qunell, R. Reilly \\ Fermilab \\ P.O. Box 500 \\ Batavia IL 60510
}

INTRODUCTION Presently, there are 6 proton and 6 antiproton bunches used for collider operation in the Fermilab Tevatron. As the number of particles in these bunches increases, experimenter's detectors begin to saturate. To alleviate this situation, protons and antiprotons will be redistributed in 36 bunches instead of 6 to reduce the number of interactions per crossing. In order to carry this out, the rise and fall times of the Tevatron antiproton injection kicker which deflects the antiprotons onto the closed orbit must be reduced to accommodate the increased number of bunches circulating in the machine.

To function in its new capacity, the kicker magnet system must meet the requirements in Table I:

Table I

System Design Parameters

\begin{tabular}{|c||c|}
\hline $\int$ Bdl & $0.508 \mathrm{~T} \mathrm{~m}$ \\
\hline Space available & $5.8 \mathrm{~m}$ \\
\hline Horizontal aperture & $50.8 \mathrm{~mm}$ \\
\hline Vertical aperture & $40.6 \mathrm{~mm}$ \\
\hline Good field $( \pm 0.1 \%)$ width & $35 \mathrm{~mm}$ \\
\hline Field rise/fall times & $395 \mathrm{nsec}$ \\
\hline Flattop & $1260 \mathrm{nsec}$ \\
\hline Flattop stability & $\pm 1 \%$ \\
\hline Post flattop stability & $\pm 1 \%$ of full field \\
\hline
\end{tabular}

To meet these criteria, it is necessary to reduce the inductance per unit length as seen by the driving source in order to achieve the necessary propagation time through the magnet, For a given aperture, this can be readily done using a picture frame design powered with two pulses of opposite polarity. Two magnets are required, each with a magnetic length of $2.41 \mathrm{~m}$. The relevant parameters for the magnet are listed in Table II.

Each of the two magnets will be powered by a pair of pulsers located in the D48 service building. Each pulser will use spark gap switches and RG-220 type coaxial cables as pulse forming lines. For this application in which the number of pulses per day is relatively low, the lifetime of the spark gap is sufficient. The spark gap switch is compact which enables us to put the three additional pulsers into the existing service building. A shunt "tail biter" switch will be included in each pulser to reflect the energy which spills out immediately after the pulse due to dispersion in the PFL cables. This energy will be dissipated in a resistor at the far end of the PFL cable. The overall schematic is illustrated in Figure 1. 
Table II

Magnet Design Parameters

\begin{tabular}{|l||l|}
\hline Magnetic length & $2.41 \mathrm{~m}$ \\
\hline Gap height & $5.72 \mathrm{~cm}$ \\
\hline Gap width & $6.50 \mathrm{~cm}$ \\
\hline Peak field & $1055 \mathrm{G}$ \\
\hline Peak current & $4800 \mathrm{~A}$ \\
\hline $\begin{array}{l}\text { Characteristic } \\
\text { impedance }\end{array}$ & $6.25 \Omega$ \\
\hline Field propagation time & $275 \mathrm{nsec}$ \\
\hline Number of cells & 68 \\
\hline Inductance per half cell & $25.3 \mathrm{nH}$ \\
\hline Capacitance per half cell & $645 \mathrm{pF}$ \\
\hline
\end{tabular}

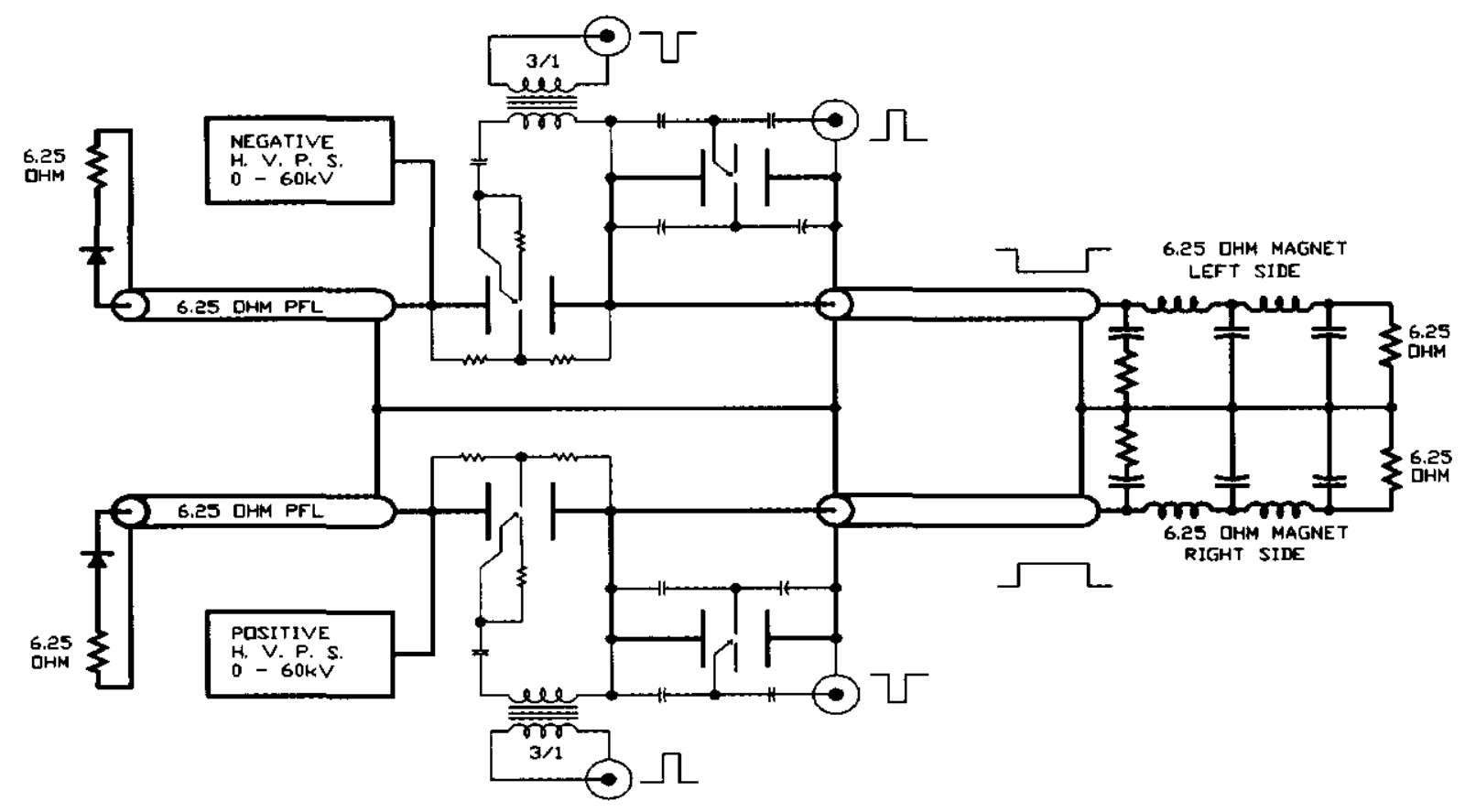

Multibunch Kicker Magnet System Schematic

Figure 1

MAGNET DESIGN Of the 230 inches available for this magnet system, some 40 inches are earmarked for connections, flanges, pump-out ports, etc. The remaining 190 inches or $4.82 \mathrm{~m}$ dictate that we must generate a field given by:

(1)

$$
\mathrm{B}_{\max }=[\mathrm{Bdl} / \mathrm{l}=.508 \mathrm{Tm} / 4.82 \mathrm{~m}=0.1053 \mathrm{~T}
$$


If the reluctance drop in the ferrite is assumed to be negligable, the required peak current is:

$$
\mathrm{I}_{\mathrm{p}}=\mathrm{B}_{\max } \mathrm{g} / \mu_{\mathrm{o}}=0.1053 \times 5.72 \times 10^{-2} /\left(4 \pi \times 10^{-7}\right)=4798 \mathrm{amps}
$$

For purposes of discussion, consider the picture frame magnet design as two " $\mathrm{C}$ " magnets sharing the gap as portrayed in figure 2. Each " $\mathrm{C}$ " magnet has a length of $l / 2$ and a gap width of $w / 2$. The inductance of each of these magnets as seen by the driving source is given by:

$$
\mathrm{L}_{\mathrm{m}}=\mu_{\mathrm{o}}(l / 2)(\mathrm{w} / 2) / \mathrm{g}=4 \pi \times 10^{-7} \times 4.82 \times 6.5 \times 10^{-2} /\left(4 \times 5.72 \times 10^{-2}\right)=1.72 \mu \mathrm{H}
$$

For the sake of reliability, the cables of the PFL are operated around $60 \mathrm{kV}$. This sets the magnet impedance at:

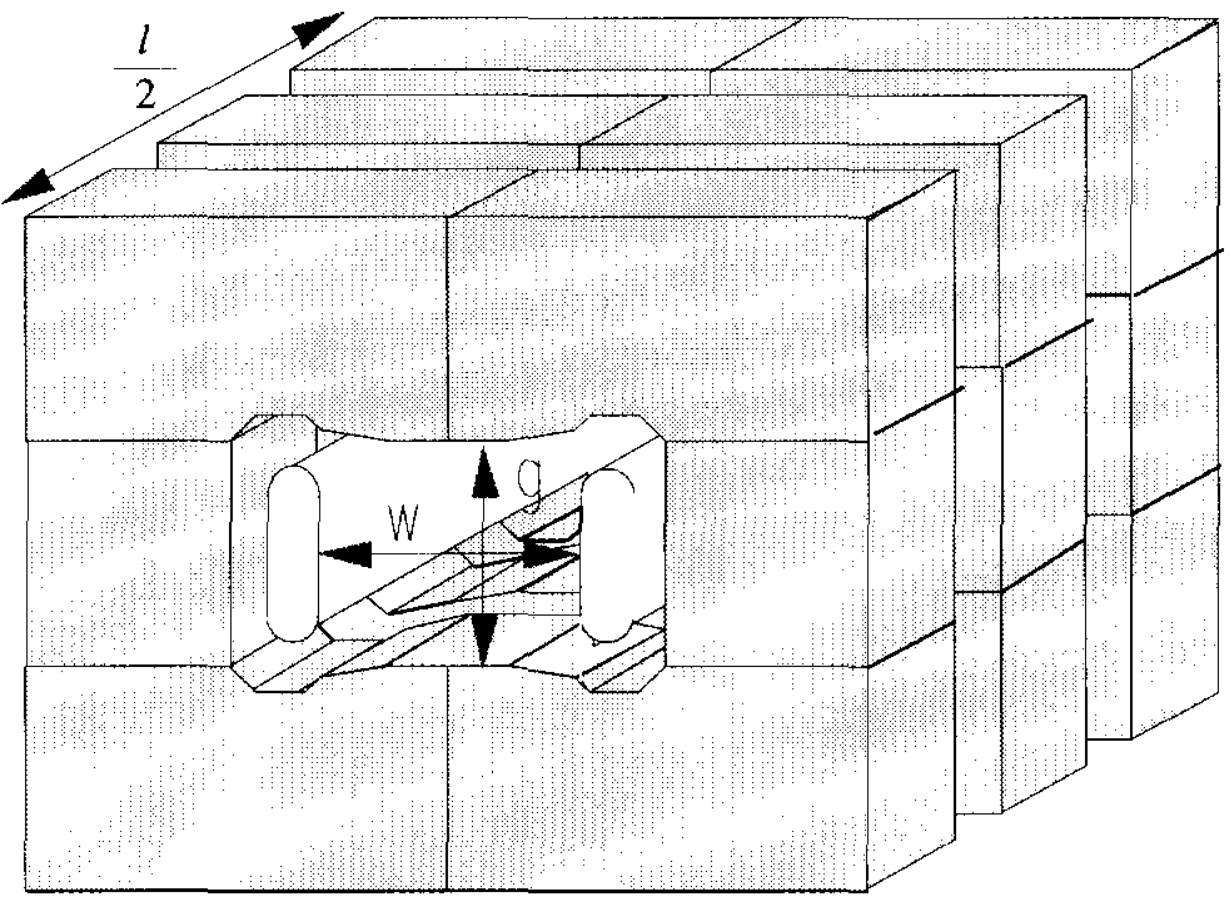

Fig. 2 - "Picture Frame" magnet

In order to achieve this impedance in a transmission line magnet, a shunt capacitance of:

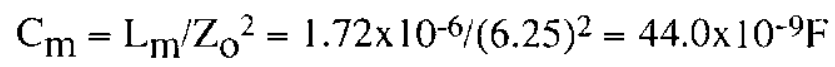

is required. The propagation time through the magnet can be calculated as: 


$$
\mathrm{T}_{\mathrm{m}}=\sqrt{\mathrm{L}_{\mathrm{m}} \mathrm{C}_{\mathrm{m}}}=\sqrt{1.72 \times 10^{-6} \times 44 \times 10^{-9}}=275 \mathrm{~ns}
$$

In the design of the previous kicker magnet, it was found that 1-inch wide ferrite pole pieces could be spaced up to 0.4 inches apart without significant effect on the field at the mid plane. This spacing does, however, increase the flux and $\mathrm{dB} / \mathrm{dt}$ in the ferrite by $40 \%$. Consider the " $\mathrm{C}$ " magnet as made up of cells, each consisting of a portion of the gap inductance and a shunt capacitance. If each cell has a physical length of 1.4 inches or $.03556 \mathrm{~m}$, then the number of cells would be:

$$
\mathrm{N}_{\mathrm{c}}=4.82 /(2 \times .03556)=68 \text { cells }
$$

Each cell has an inductance of $25.3 \mathrm{nH}$ and capacitance of $647 \mathrm{pF}$. This sets the cutoff frequency of the magnet to:

$$
\mathrm{F}_{\mathrm{c}}=1 /\left(2 \pi \sqrt{\mathrm{L}_{\mathrm{c}} \mathrm{C}_{\mathrm{c}}}\right)=1 /\left(2 \pi \sqrt{25.3 \times 10^{-9} \times 647 \times 10^{-12}}\right)=39 \mathrm{MHz}
$$

The function of the ferrite is to efficiently guide stored magnetic energy into the gap. In order to do this, the magnetization must increase to the required value as rapidly as possible for a given drive level and source impedance. To select the ferrite which best meets this criteria, samples of a standard size were obtained from four manufacturers. These samples were subject to pulsed tests where the $\mathrm{B}$ and $\mathrm{H}$ fields were measured at high drive levels, $\sim 6 \mathrm{kV}$, into a $50 \Omega$ load. With a sample that is approximately the same size and magnetic path length as one cell of the actual magnet, we should get results that can be directly applied to this magnet.

Three of the samples are for particle accelerator applications; CMD5005 by Ceramic Magnetics, Inc. ; 8C11 by Phillips Components; and PE12C by TDK. These materials performed similarly in the testing having roughly the same magnetic flux density rise time. The CMD5005 has a slightly higher saturation flux density than the other two samples. The CN20 material from Ceramic Magnetics is primarily aimed at EMI suppression and RF transformer applications. The TT71-4800 is a lithium zinc ferrite that is primarily used for microwave devices. The PE16 was also recommended by TDK as a possible material for this application. The selection of the ferrite was based on these criteria:

1. fast time to a given induction level

2. low remnant induction

3. high saturation magnetization

It should also be noted that magnetic properties for ferrites can vary by as much as $\pm 20 \%$ from batch to batch for the same material. For the magnet, one would like the reluctance drop in the ferrite to fall as rapidly as possible. The amount of energy required to drive the ferrite can be approximated by multiplying $\mathrm{B}(\mathrm{t})$ and $\mathrm{H}(\mathrm{t})$ to get the energy density. The larger the volume of ferrite, the more total energy is required to reach the desired induction level. The peak power required to reach this level will be limited by the source impedance. For the sample core, the data shows that approximately $5 \mathrm{~mJ}$ were required to reach an induction level of 1400 Gauss in $-25 \mathrm{~ns}$. The volume of ferrite in the magnetic 
circuit of a half cell is 5 times greater than the test core, therefore we can conclude that $25 \mathrm{~mJ}$ would be required for the ferrite in a half cell or $3.3 \mathrm{~J}$ for the whole magnet. This is about $0.2 \%$ of the total stored energy.

The program POISSON was used to generate a pole tip profile which would meet the required field flatness over the desired horizontal aperture. The field at the mid plane of the gap as shown in Fig. 3 is flat to within $\pm 0.05 \%$. For a $3.8 \mathrm{~mm}$ offset from the mid plane, the field is flat to within $\pm 0.1 \%$.

The propagation velocity of the electromagnetic wave which penetrates the ferrite poles of the magnet can be calculated for CMD-5005 using:

$$
\mathrm{V}_{\mathrm{f}}=3 \times 10^{8} / \sqrt{\mu \varepsilon}=3 \times 10^{8} / \sqrt{1000 \times 12} \approx 3 \times 10^{6} \mathrm{~m} / \mathrm{sec}
$$

The width of the pole piece is 2 inches $(.0508 \mathrm{~m})$ which would resonate at $27 \mathrm{MHz}$. This is slightly below the magnet cutoff frequency.

A 29-cell low voltage test magnet has been built to measure the inductance and impedance characteristics of the final design. A copper Faraday shield $.062 \mathrm{in}$. thick was placed vertically down the centerline of the test magnet to enable us to perform realistic

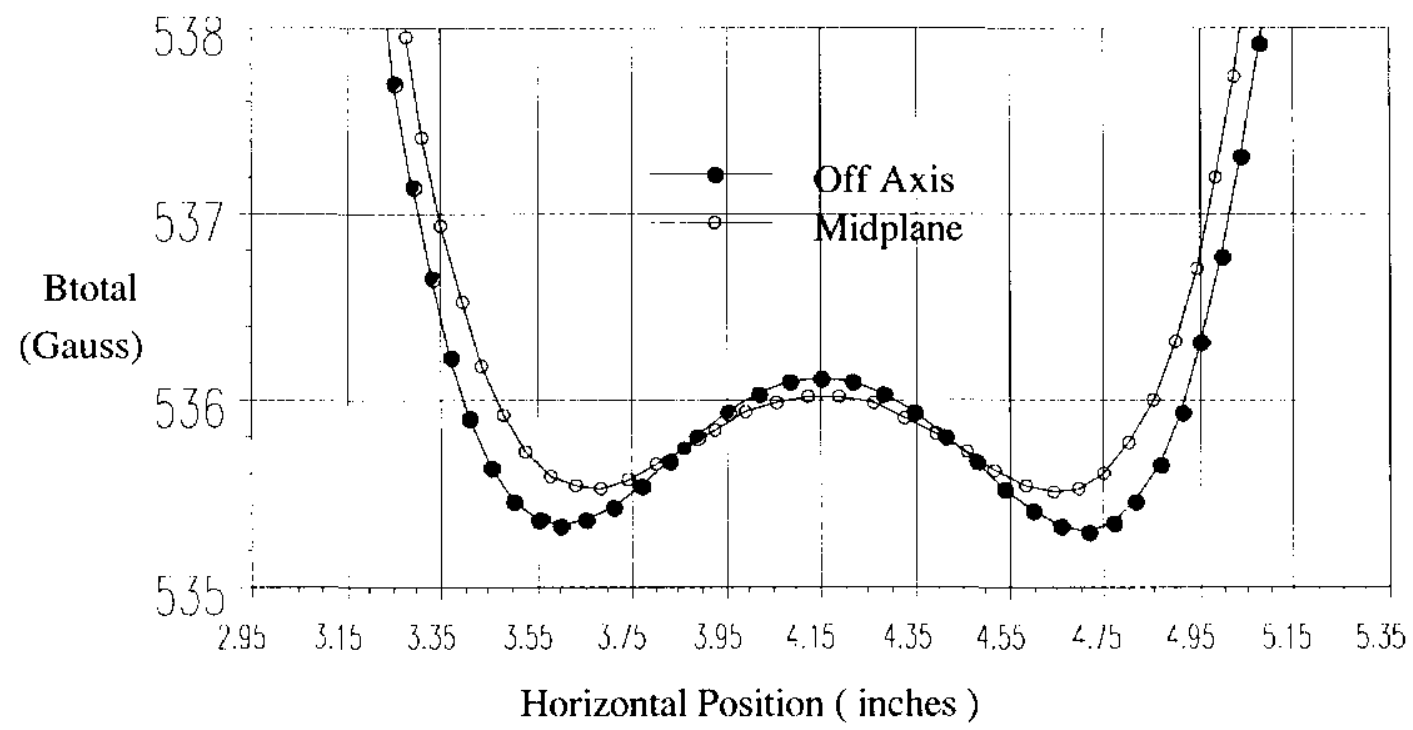

Figure 3 - Comparison of POISSON Results

Midplane and $0.14^{\prime \prime}$ Off Axis

measurements on the $\mathrm{C}$ - shaped half-cell shown in Figure 2. Impedance measurements were made using an HP 4194A Impedance/Gain-Phase Analyzer. Initial measurements were made on 13 half cells of the structure with no ferrite. Additional inductance measurements were made as successive half cells were loaded with ferrite. From this data, we found the average inductance of a half cell to be $25.8 \pm 0.3 \mathrm{nH}$. A measure of the 
leakage or fringing field comes from the difference in incremental inductance between the first ferrite loaded cell measurement and all successive measurements. Repositioning the ferrite from adjacent to distant cells also permits us to measure the mutual coupling between cells directly. In both cases it was found to be $7.0 \mathrm{nH}$. Although the measured cell inductance calls for a shunt capacitance of $660 \mathrm{pF}$, the best pulse response was found with $640 \pm 5 \mathrm{pF}$ of shunt capacitance per half cell and the flattest frequency response was found with $650 \pm 5 \mathrm{pF}$.

The displacement current through the shunt capacitor must pass between the backlegs of two adjacent ferrite pole pieces. This current generates flux in opposite directions in these two pole pieces as shown in Figure 4. This effect increases the inductance in serics with the capacitor. To minimize this effect, these two backlegs can be cross-coupled to effectively cancel this flux. Cross-coupling, then, effectively puts a negative inductance in series with the capacitor. The peak current in a typical winding was measured under pulse conditions and is shown in Figure 5a. When scaled to a magnet input voltage of $30 \mathrm{kV}$, this current would be $240 \mathrm{~A}$ peak. A resistance of $10 \Omega$ was introduced in each of these circuits to provide damping of the ringing of the half cell current. This provides the results shown in Figure 5 b.

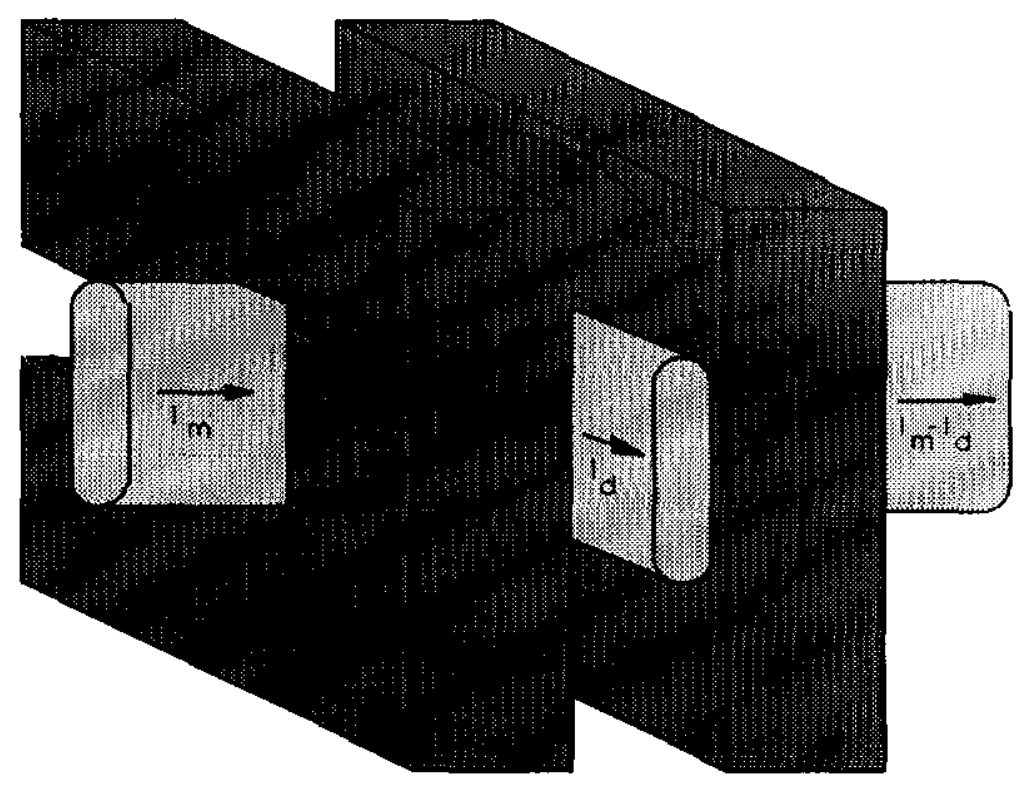

Flux distribution due to primary and displacement currents in cell components

Figure 4

The capacitor located at the input side of the first cell has a value of $320 \mathrm{pF}$ and has a series resistor equal to $\mathrm{Z}_{\mathrm{O}}$. This network terminates frequency components of the input pulse which are above the magnet cutoff frequency. 


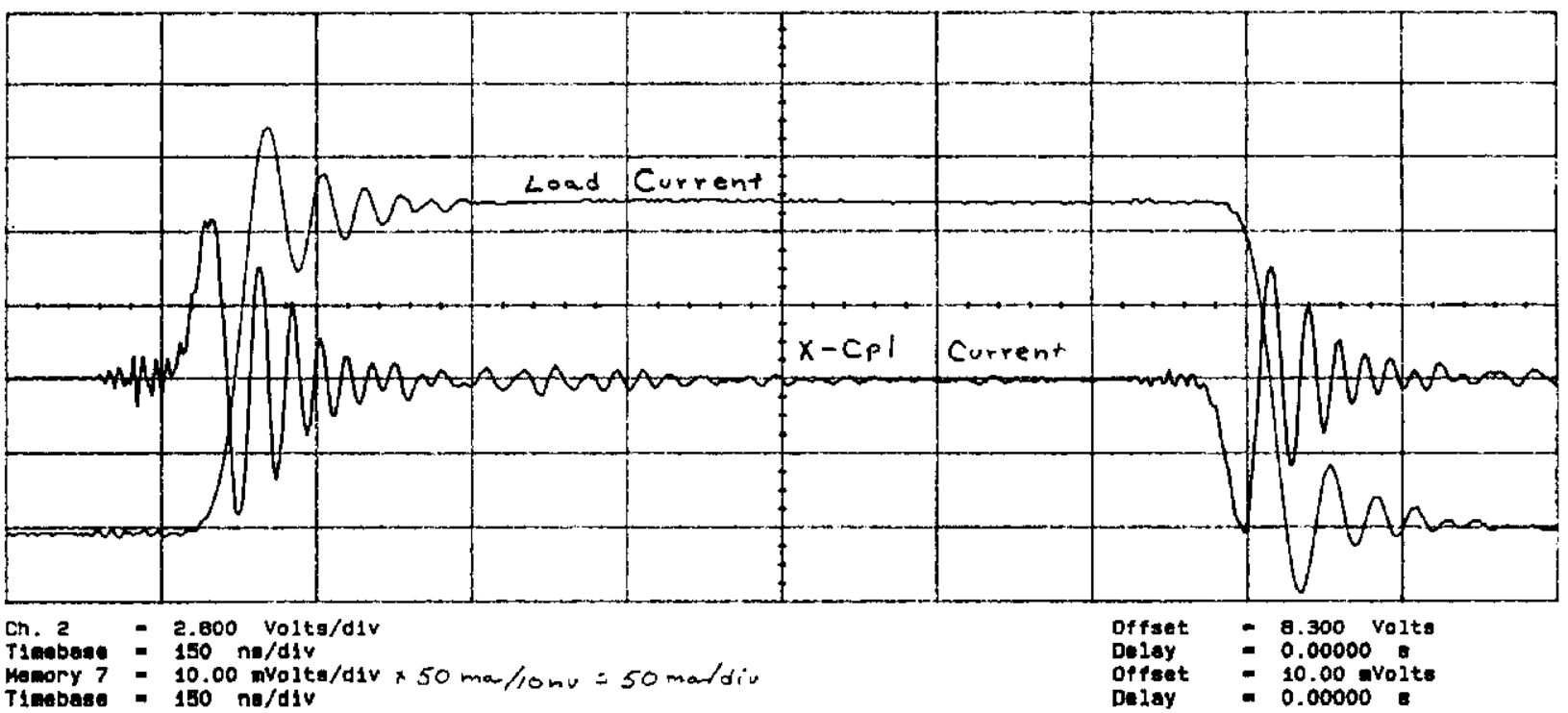

Figure 5a - Cross coupling winding current

0.00000

$750.000 \mathrm{~ns}$

1.50000 us

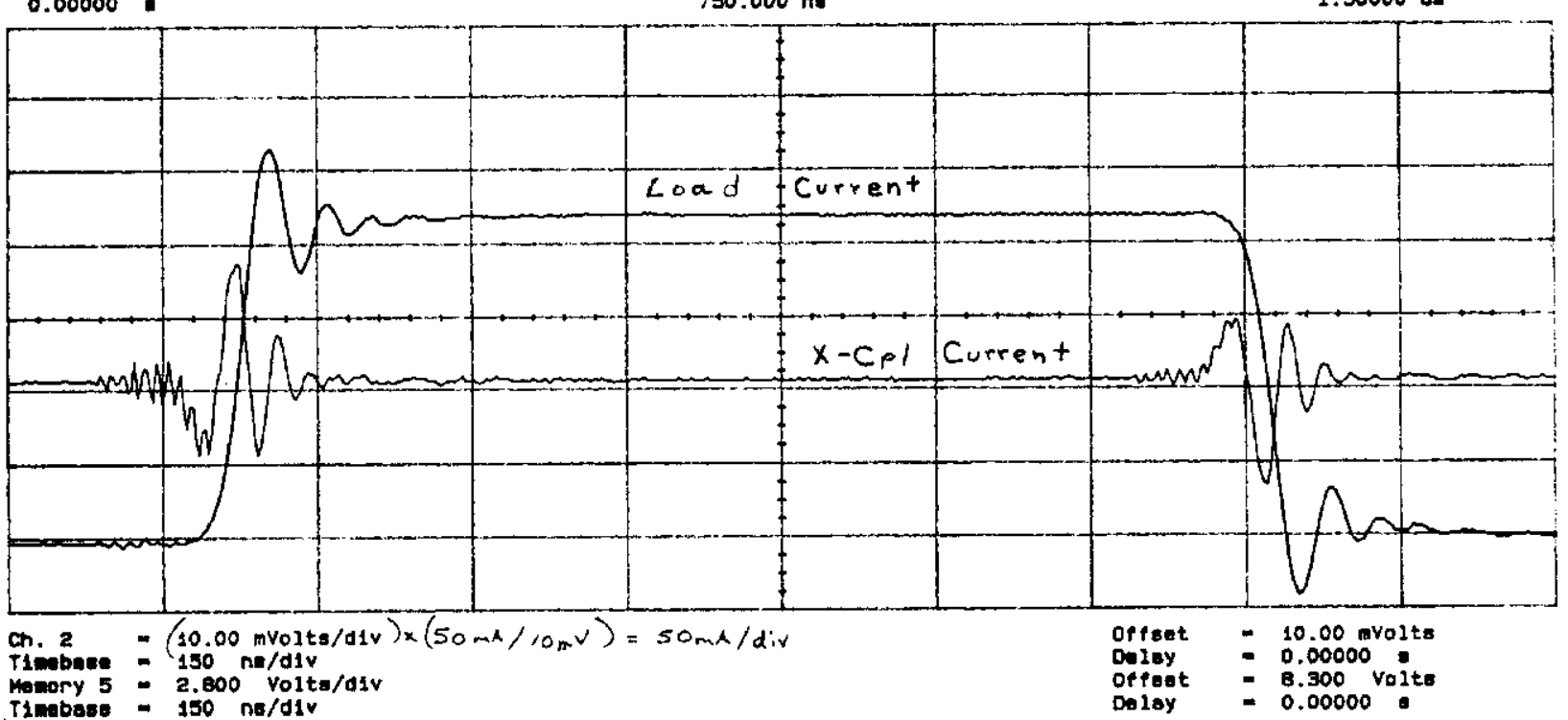

Figure $5 b$ - Cross coupling winding current with $10 \Omega$ resistor 
The shunt capacitors used in this magnet are a parallel plate design. They are required to operate at voltages of $35 \mathrm{kV}$ peak and maintain a stable capacitance over their operating lifetime. Physically, each must fit within the 0.4 inch space between adjacent ferrite pole pieces. Such a design offers the lowest practical inductance. The perimeter of the capacitor is tailored to clear the beam pipe and the ferrite cross-coupling leads yet make electrical contact with both the center conductor and the outer case. Each capacitor is essentially a six layer printed circuit board which uses a glass reinforced polyimide dielectric. It is designed to be mechanically symmetrical about its center which balances the internal stresses generated during its fabrication. Each conducting surface is made from double sided C-stage material which is $.012^{\prime \prime}$ thick with 2 oz of copper cladding. Between the 3 conducting surfaces which are connected as two capacitors in parallel, are layers of $\mathrm{B}$ and $\mathrm{C}$ stage material which form the working dielectric. The thickness of this dielectric is $0.090^{\prime \prime}$ which stresses it to $25 \%$ of its rated breakdown voltage of $1600 \mathrm{v} / \mathrm{mil}$. Since there are no intermediate conducting layers to grade the electric field at the edges, the electric field stress is near the rated value at the conductor interface. A prototype run of 12 of these capacitors was initially tested for corona extinction at voltages from 28$37 \mathrm{kV}$. After pulsing them to $35 \mathrm{kv}$ for $5 \times 10^{6}$ shots, the corona extinction level dropped slightly on some devices. The threshold of our measurement was $5 \mathrm{pC}$.

Another unique feature of this magnet system is the fact that the load resistors are an integral part of the magnet structure. This has the advantage of eliminating reflections from the cables and their associated connectors normally used with external resistors. Eight $50 \mathrm{ohm}$ resistors are paralleled to achieve a $6.25 \mathrm{ohm}$ load impedance. These resistors are Carborundum 'rod' type resistors with no-arc corona terminals. Manufacturers of high voltage resistors will not specify resistors to better than $\pm 5 \%$. Carborundum, however, has agreed to match sets of 8 resistors for use to a tolerance of $0 /+4 \%$ at a minimal cost. This will allow us to trim the load with a ninth parallel resistor to the design value. The maximum energy dissipated in each resistor is 28.5 Joules. This system is pulsed about 18 times a day, spaced several minutes apart. This results in a negligible average power dissipation in the load resistors. The resistors are placed inside aluminum tubes to minimize inductive effects. The diameter of these tubes is the minimum allowable to have an adequate safety margin for high electric field stress regions. The resistors are then potted in silicone rubber dielectric media which results in an impedance of $23 \Omega$ which is a compromise between the $50 \Omega$ seen at one end of the resistor and $0 \Omega$ at the other. The termination is less than $1 \mathrm{ft}$. long which corresponds to a propagation time of $1.5 \mathrm{~ns}$ in Sylgard. A current viewing resistor (CVR) is used to monitor the current in the termination. The CVRs selected offer a $\mathrm{lns}$ rise time and a $3 \mathrm{~J}$ rating at $0.005 \mathrm{ohms}$

The resistors will be pulsed to $30 \mathrm{kV}$. In practice, the voltage coefficient for high voltage pulses has been observed to be small, and is often neglected.

Ideally, the load is matched to the impedance of the magnet for the frequency spectrum of the pulse which is shown in Figure 6. The frequency and phase response of the prototype load are shown in Figure 7. 


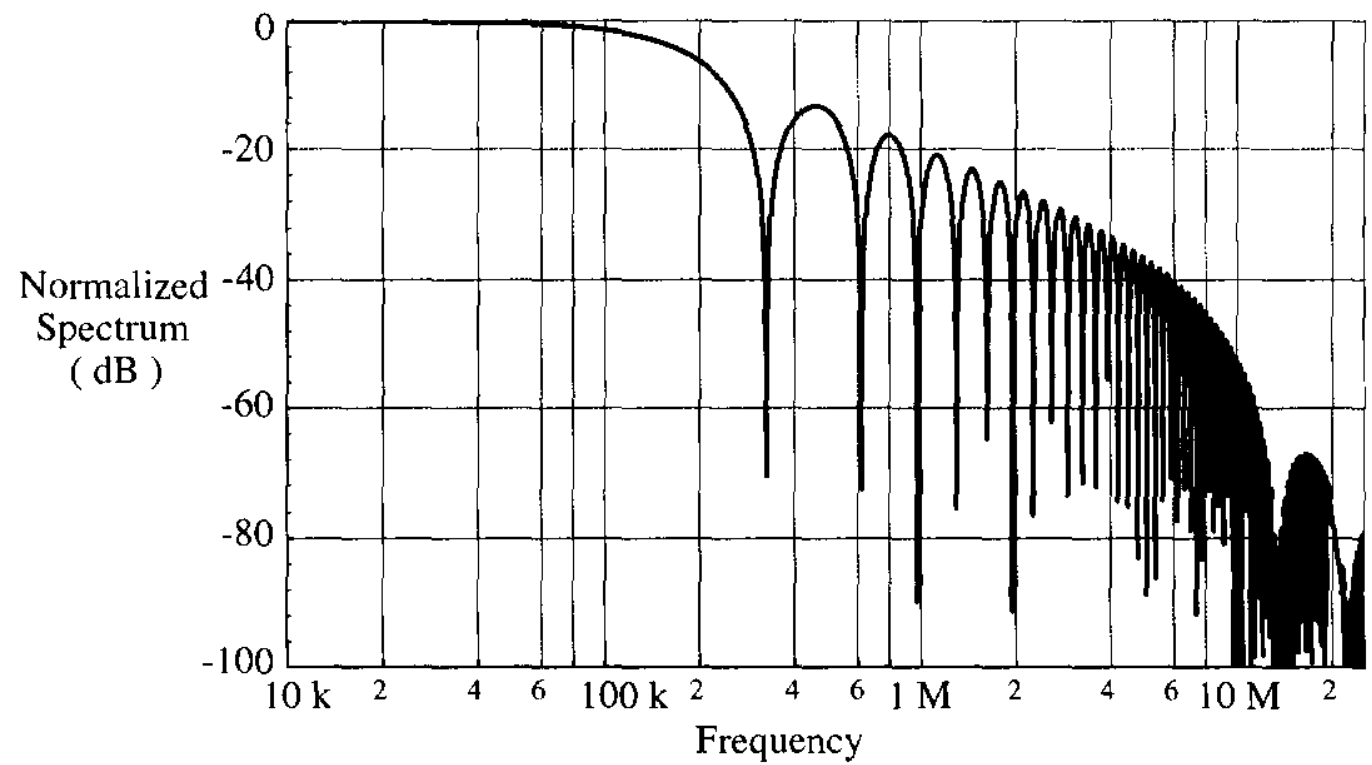

Figure 7 - Frequency spectrum of the load current pulse

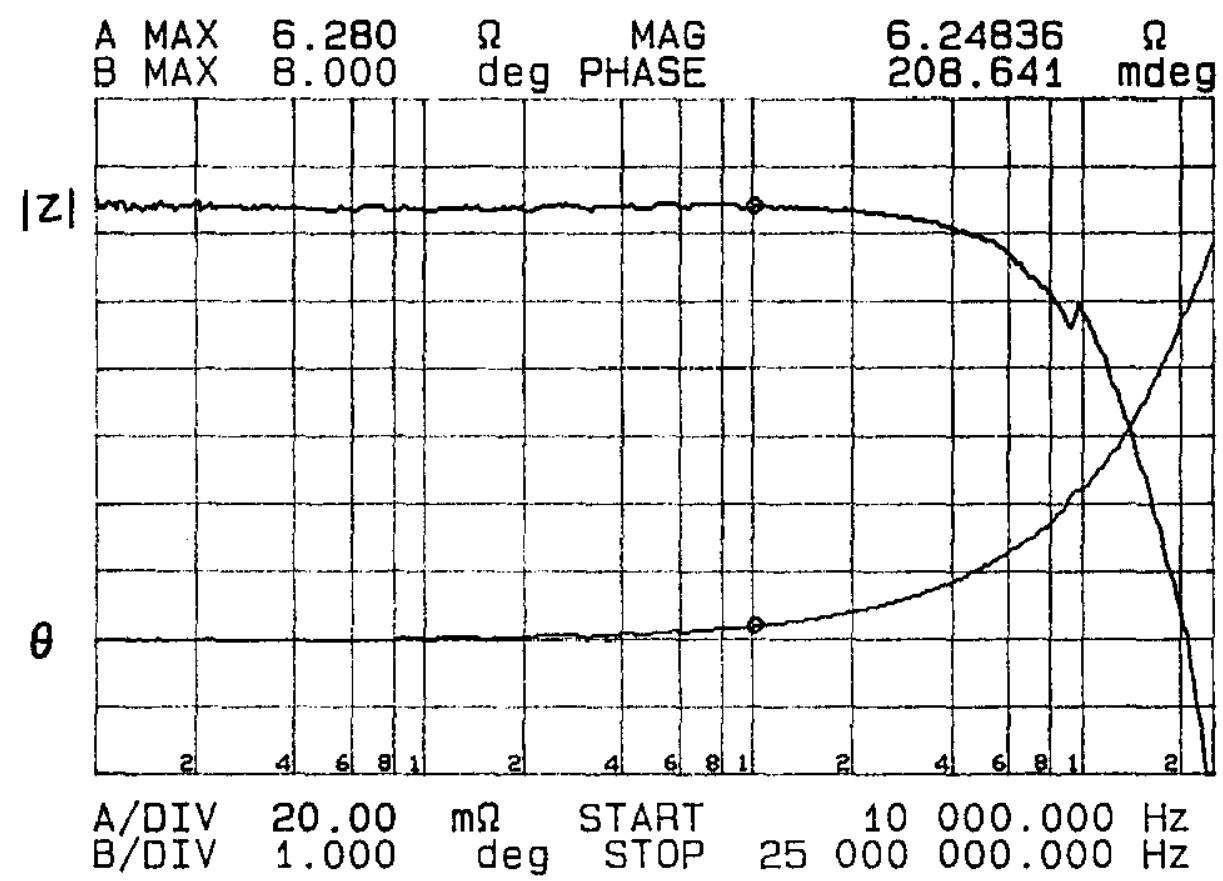

Figure 7 - Frequency and phase response of the prototype load 
The beam tube is a ceramic tube of $2.240^{\prime \prime} \times 1.930^{\prime \prime}$ nominal outside dimensions and 0.150 " wall thickness. The length of the ceramic is approximately $100^{\prime \prime}$. Because of the difficulty of producing straight tubes in such a length and the likelihood of curved or bowed tubes, all tubes supplied by the vendor will be required, before attaching the flanges, to fit into a volume of $2.520^{\prime \prime} \times 2.230^{\prime \prime} \times 100^{\prime \prime}$ long in the free unstressed state. The alumina specified is Alumina $99.8 \% \mathrm{Al}_{2} \mathrm{O}_{3}$, a strong recrystalized high-alumina fabricated by casting. The ends will have brazed Kovar flanges, transition pieces, stainless 6 " rotatable conflat flanges, and a bellows at one end.

The high current conductors will be OFHC copper, 1/2" $\times 1-3 / 4^{\prime \prime}$ with full radius on top and bottom. Grooves will be cut to accept the capacitor center tabs. The high voltage conductor will have large end flags for attaching the HV connectors at one end and the load resistors at the other. These flags and their associated hardware will be potted in detachable end housings.

PULSER DESIGN A triggered spark gap was chosen for this design instead of a thyratron for a variety of reasons. Most importantly, spark gap systems are much smaller than thyratron systems. Spark gaps can transfer more energy at higher levels of voltage and current than thyratrons. Also, spark gaps are lighter and cheaper than thyratrons. There is also no filament or reservoir power, and thus no warm up time. Finally, spark gaps are more robust and can withstand larger inverse currents typical in tail-biter circuits. Disadvantages of spark gaps include low repetition rates, lower lifetime, necessity of a pressurized gas system, and finally the need for a high voltage trigger system.

The nominal PFL design voltage of $60 \mathrm{kV}$ is also the voltage which must be held off by the spark gap. The Maxwell \#40264 gap chosen for this application is rated for operation from $25 \mathrm{kV}$ to $100 \mathrm{kV}$, at a maximum of $100 \mathrm{kA}$. The minimum length of the PFL cables is determined by the pulse length and is given by:

$$
\begin{aligned}
& \mathrm{t}_{\mathrm{pfl}}=\mathrm{t}_{\text {flattop }}+\mathrm{t}_{\text {field rise time }}=1260 \mathrm{~ns}+395 \mathrm{~ns}=1655 \mathrm{~ns} \\
& l_{\mathrm{pfl}}=\mathrm{t}_{\mathrm{pfl}} \times .659 / 2=545 \mathrm{ft}
\end{aligned}
$$

There will be $8 \mathrm{RG}-220$ type cables in parallel for an impedance of $6.25 \Omega$. The actual length will be somewhat longer than this minimum length to insure proper operation of the tail-biter spark gap.

The capacitance of the PFL cables for each pulser is:

$$
C_{p f l}=8 \times C_{\text {cable }} \times l_{p f l}=8 \times 29.5 p F / f t \times 545 f t=0.13 u F
$$

The energy stored in the capacitance of PFL is also the energy transferred by the spark gap on each pulse. The energy can be calculated as:

$$
W_{p}=\left(I_{p}\right)^{2} \times Z_{0} \times t_{n f l}=4798^{2} \times 6.25 \times 1.655 \times 10^{-6}=239 J
$$


The total lifetime for spark gaps is typically rated in Coulombs. The charge stored in the cable capacitance determines the estimated lifetime of the spark gap. It can be shown to be:

$$
Q_{p}=C_{p f l} \times V_{p l l}=I_{p} \times t_{n f l}=4798 \times 1.655 \times 10^{-6}=0.008 C
$$

The maximum energy transfer allowable for the Maxwell gap is $0.3 \mathrm{C}$ per shot. For the Maxwell gap, this is $(0.3 \mathrm{C}) *(10,000$ shots $)$, or $3000 \mathrm{C}$, maximum. This, in turn, results in an estimated lifetime as follows:

$$
\text { Number of shots }=3000 \mathrm{C} / 0.008 \mathrm{C}=375,000 \text { shots }
$$

This is a maximum rating. These shots are typically spaced approximately 1 minute apart for injection. Spark gaps are typically limited to repetition rates of about 100 $\mathrm{Hz}$ which is adequate for this application.

The rise time of the pulse is determined by the electrical properties of the pulser, specifically, the inductance related to the geometry of the tank. This inductance $(125 \mathrm{nH})$ has been measured by several methods which also agree with the calculations based on geometry alone.

The time constant and rise time are thus given by:

$$
\tau=\mathrm{L} / 2 \mathrm{Z}=125 \mathrm{nH} /(2 \times 6.25 \Omega)=10 \mathrm{~ns}
$$

Thus, It takes approximately 5 time constants, or $50 \mathrm{~ns}$, to get within $1 \%$ of the maximum value based on this time constant, neglecting any mismatches in the load. Experimental data agrees with these results. The pulser is constructed in a coaxial geometry to minimize the inductance while giving adequate clearance for high voltage constraints.

Prefires are another consideration for spark gaps. For this reason, it is recommended that the spark gaps are charged to the operating voltage just before a pulse is required, and the charging supply is disabled immediately following the pulse. This type of operation is also beneficial for the various other components which operate at high voltages during charging, especially the PFL cables and its connectors. The power supplies used for charging must have the necessary control features, and be able to charge the PFL's in a short period of time. Glassman power supplies were chosen for these features, as well as their reliability. They are rated to $75 \mathrm{kV}$ at $50 \mathrm{~mA}$. Typically, one power supply charges two PFL's. The PFLs are charged through a series resistance which provides satisfactory isolation of the power supply during the pulse. 
This spark gap has two "gaps", one between each of two main electrodes and a midplane. This midplane has a small hole in the center which contains a small pin. This pin generates plasma in the region of the midplane electrode hole to reduce jitter during the trigger process. This midplane is biased by resistors at half of the PFL voltage. Application of a high voltage trigger pulse to the midplane electrode causes a breakdown to occur in two stages simultaneous with the UV irradiation. For lowest jitter, a trigger pulse of opposite polarity to the PFL voltage is used. The PFL electrode breaks down first, which in turn over voltages the second gap between the midplane and load electrode, thus breaking down that gap.

To trigger the spark gap, a Maxwell trigger generator is used. It is necessary to incorporate a high voltage pulse transformer to isolate the trigger circuit from the spark gap. This is necessary since the main switch floats in series between the PFL and the load. The trigger pulse transformer is a coaxial 3:1 step down design with the primary as the center conductor. The primary consists of 3 turns of $60 \mathrm{kV}$ silicon rubber insulated wire strung thru three single helical loops of refrigeration tubing connected in parallel to form the secondary. Resistors are placed on both sides of the transformer to maintain a high common mode impedance for the trigger circuit. We were able to achieve a jitter of $7.4 \mathrm{~ns}$ for 32 shots, and a flattop ripple of $1 \%$ peak-to-peak. A typical current pulse is shown in Figure 8.

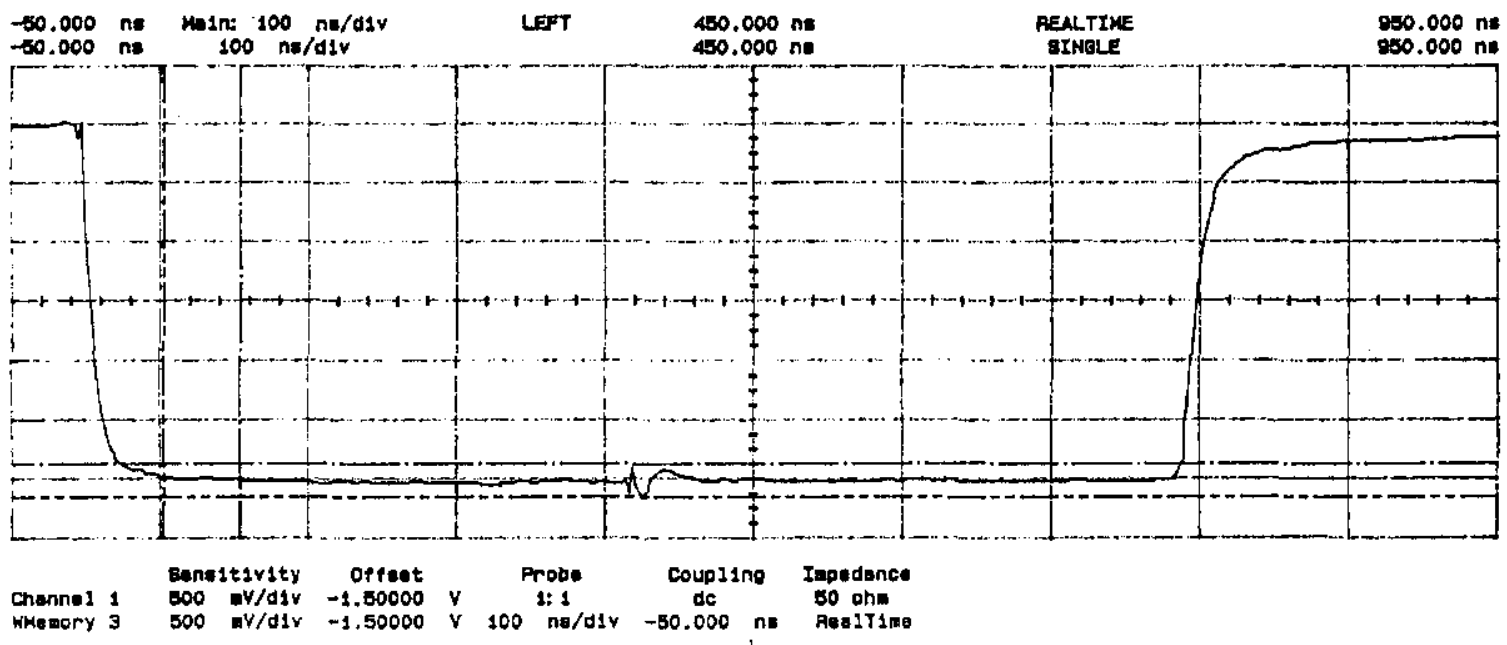

Figure 8 - Typical load current pulse

High voltage requirements necessitate the use of a dielectric with adequate breakdown strength. In this system, the pulser is pressurized with Sulfur Hexafluoride to about 12 psig which provides a breakdown strength greater than that of transformer oil.

To facilitate the making of electrical connections, a 'quick-disconnect' type of connector was desired for the high voltage coaxial cables. SLAC has developed a suitable connector in cooperation with Isolation Designs.[1] It is rated to be operated at $60 \mathrm{kV}$ dc. The Fermilab version has a slightly modified end terminal and a revised 'cord grip' to 
facilitate cable installation. Electrically, they have been designed to be as short as possible to maintain a low inductance.

The expotential like 'tail' at the end of the pulse due to the $1 / \sqrt{\mathrm{f}}$ skin effect losses in the cables requires the use of a second 'tail biter' switch to short the output of the pulser to ground at the end of the pulse. See Figure 1. This will reduce the fall time of the output pulse to the order of the rise time, about $50 \mathrm{~ns}$. The tail biter will also use a spark gap switch. A spark gap similar to that used for the main switch can be used with a capacitive divider network to provide the necessary midplane biasing. Preliminary tests indicate that such an approach does not cause this gap to prefire and that it will in fact trigger on demand.

Resistors in the back termination for the PFL are similar to those used in the magnet load since they must dissipate the PFL stored energy under fault conditions. The series diodes selected for this termination must also handle the full load current of $4798 \mathrm{~A}$ for $1.58 \mu \mathrm{s}$ under fault conditions. Unitrode UGE-7.5 diodes which have a non repetitive sinusoidal surge current of $200 \mathrm{~A}$ and a peak inverse voltage of $7.5 \mathrm{kV}$ were selected for this service. Two stacks of 12 diodes provide an inverse rating of $90 \mathrm{kV}$. These diodes require no external dividers. To insure current sharing, half of the PFL cables will be terminated thru each diode stack.

No discussion of a delay line pulser would be complete without addressing the dispersion effects caused by the skin effect losses in the PFL and interconnecting cables. The step response of a coaxial cable in which the skin-effect losses produce an attenuation whose magnitude in $\mathrm{dB}$ varies as the square-root of frequency can be approximated by:[2]

$$
\mathrm{E}_{0}=\mathrm{E}_{\mathrm{i}}\left[1-\operatorname{erf}\left(\frac{1.018 \times 10^{-8} \times \mathrm{A} \times l}{\sqrt{\mathrm{t}}}\right)\right]
$$

where $\mathrm{A}$ is the cable attenuation in $\mathrm{dB} / 100 \mathrm{ft}$. at $1000 \mathrm{mHz}, l$ is the cable length in $\mathrm{ft}$. and $\mathrm{t}$ is the time in sec. The step response of a coaxial cable used as a PFL can be approximated in similar fashion by the relation:

$$
\begin{aligned}
\mathrm{E}_{\mathrm{o}}= & \mathrm{E}_{\mathrm{PF} \cdot \mathrm{L}}\left[1-\operatorname{erf}\left(1.018 \times 10^{-8} \times \mathrm{V}_{\mathrm{p}} \times \mathrm{A} \sqrt{\mathrm{t}}\right)\right] \\
& 0 \leq \mathrm{t} \leq \mathrm{T}_{\mathrm{PFl} .}
\end{aligned}
$$

We can, therefore, combine these to approximate the transient performance of this system by the expression:

$$
\begin{gathered}
\mathrm{E}_{\mathrm{t})}=\mathrm{E}_{\text {PFl }}\left[1-\operatorname{erf}\left(1.018 \times 10^{-8} \times \mathrm{V}_{\mathrm{p}} \times \mathrm{A} \sqrt{\mathrm{t}}\right)\right] \times\left[1-\operatorname{erf}\left(\frac{1.018 \times 10^{-8} \times \mathrm{A} \times l}{\sqrt{\mathrm{t}}}\right)\right] \\
0 \leq \mathrm{t} \leq \mathrm{T}_{\mathrm{PFL}}
\end{gathered}
$$


where $l$ is the length of the cable between the magnet and the pulser. At the end of the pulse, the response is described by (20) with $l$ equal to twice the physical length of the PFL plus the cable length between pulser and magnet. The results of this expression assuming a step response (ideal switch) and $l=100 \mathrm{ft}$ are shown in Figure 9.

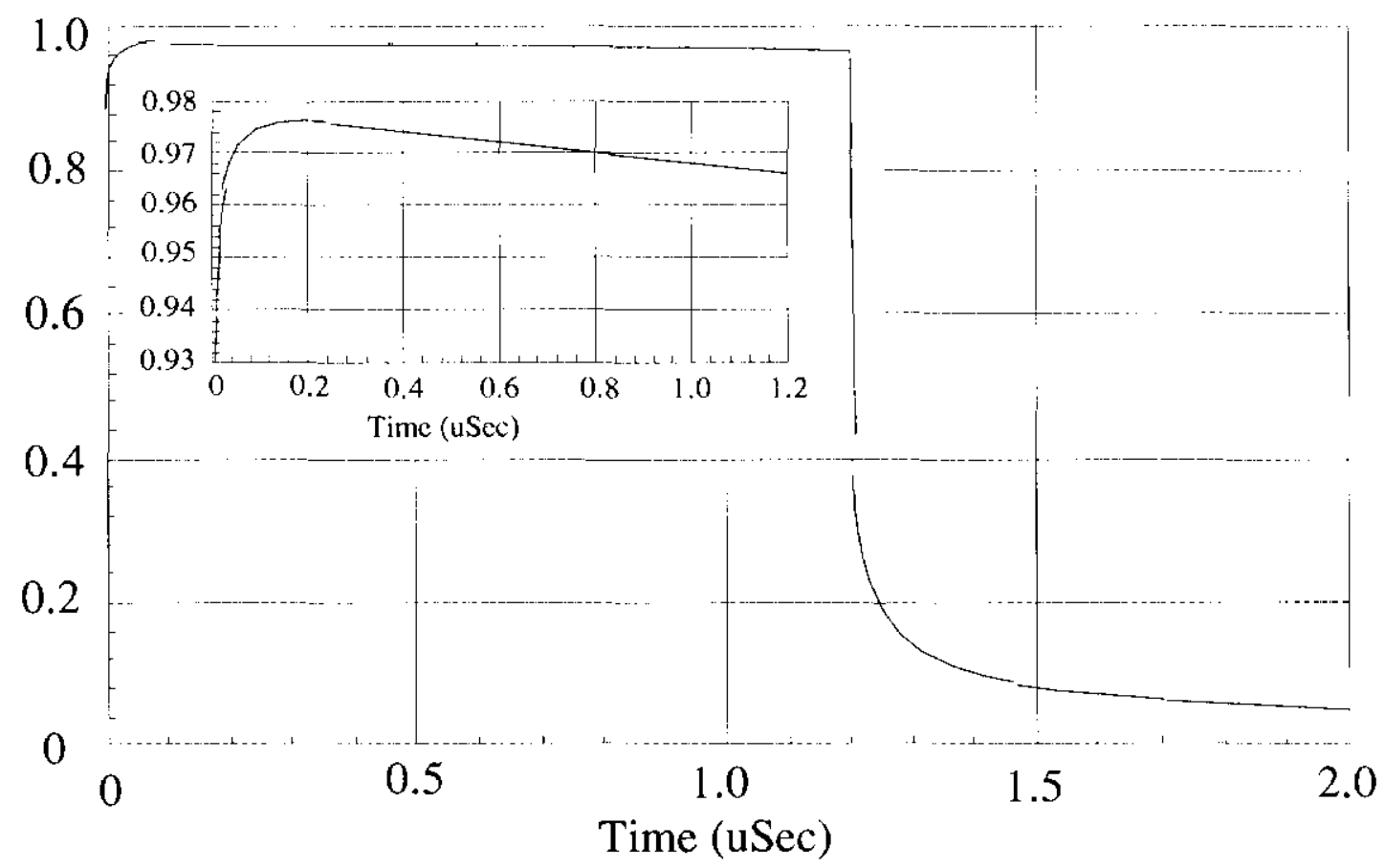

Figure 9 - Normalized response of kicker system using a PFL with skin effect losses

\section{References}

1. K. Harris et al., "High Voltage Pulse Cable and Connector Experience in the Kicker Systems at SLAC," Proc. of 1991 IEEE Particle Accel. Conf., San Francisco, pp 3159-3161

2 O. Kerns et al., "Pulse Response of Coaxial Cables," Lawrence Radiation Lab. Counting Handbook, June 1964. 